\title{
Cost reduction, entry, and the interdependence of market structure and economic growth
}

\author{
Pietro F. Peretto* \\ Department of Economics, Duke University, Durham, NC 27708, USA
}

Received 12 December 1994; received in revised form 13 November 1997; accepted 27 January 1998

\begin{abstract}
I study the joint determination of market structure and growth in an oligopolistic economy. Firms run in-house R\&D programs to produce over time a continuous flow of cost-reducing innovations. In symmetric equilibrium, the relation between market structure and growth has two aspects. First, a larger number of firms induces fragmentation of the market and dispersion of R\&D resources. This prevents exploitation of scale economies internal to the firm and slows down growth. Second, the number of firms changes with market and technology conditions and is endogenous. In particular, R\&D spending is a fixed cost and there is a negative feed-back of the rate of growth on the number of firms. The explicit consideration of the interdependence of market structure and growth identifies a fundamental trade-off between growth and variety that produces interesting results. For example, the scale effect is bounded from above and converges to zero when the number of firms is large. Moreover, the market grows too little and supplies too much variety. The inefficiency is not due to technological externalities but to oligopolistic pricing and the interaction between R\&D and entry decisions. (C) 1999 Elsevier Science B.V. All rights reserved.
\end{abstract}

JEL classification: E10; L16; O31; O40

Keywords: Entry; Growth; Market structure; R\&D; Technological progress

\section{Introduction}

Growth theorists have investigated extensively the idea that technological progress is endogenous and driven by market forces. General equilibrium (GE)

*E-mail: peretto@econ.duke.edu 
models developed to explain these forces depart from the traditional theory of growth. Since innovation requires profit-seeking firms to undertake up-front research and development $(R \& D)$, the factors determining the incentives to undertake $\mathrm{R} \& \mathrm{D}$ in imperfect markets are central to the seminal theories of Romer (1990), Grossman and Helpman (1991), and Aghion and Howitt (1992). These contributions, however, downplay the role of market structure. In contrast, an important strand of literature in Industrial organization (IO) argues that market structure is a key factor determining R\&D investment because it captures features of the business environment, like the size and number of firms, barriers to entry, and diversification. These factors determine market rivalry which, in turn, determines the opportunities and constraints that firms face when planning R\&D. ${ }^{1}$

The relationship between market structure and growth has two aspects. First, market structure determines the behavior of profit-seeking firms by affecting the returns to innovation. The private and social benefits generated by technological progress and the performance of the economy vary with market structure as market rivalry varies. In addition, the size and number of firms change in response to market and technology conditions. Market structure, therefore, is endogenous and induces feed-backs that are a crucial determinant of the performance of the economy. ${ }^{2}$

In this paper, I explore the interdependence of market structure and growth, heretofore neglected by the literature. I consider a one-sector economy where oligopolistic firms sell differentiated consumption goods. In symmetric equilibrium, the number of firms determines the two dimensions of market structure that have been the focus of IO studies: concentration and firm size (relative to the size of the market). This property allows me to focus on only one variable to

\footnotetext{
${ }^{1}$ The literature on market structure and innovation is reviewed by Kamien and Schwartz (1982), Baldwin and Scott (1987), Cohen and Levin (1989), and Scherer and Ross (1990, Chapter 17). In GE theory, the term 'market structure' refers to the set of institutions that describe how each commodity in the economy is traded. In this model, the trading institution for consumption goods is an oligopoly and the trading institution for labor services and consumption loans is perfectly competitive. In IO terminology, the term 'market structure' denotes, among other factors, the size distribution and number of firms in a specific market (see, e.g., Scherer and Ross, 1990, Chapter 1; Tirole, 1988, Chapter 1).

${ }^{2}$ See Schumpeter (1942, Chapter 7). Seminal developments of this idea are Loury (1979), Lee and Wilde (1980), Dasgupta and Stiglitz (1980), and the evolutionary theory of Nelson and Winter (1982). Early researchers developed the 'Schumpeterian hypotheses' to translate Schumpeter's verbal arguments into empirically testable relationships. They posited a causal relationship between industry or firm rates of R\&D investment and/or innovation (dependent variables) and concentration or firm size (independent variables). Later researchers included an additional equation, representing the zero-profit condition, to capture the endogeneity of concentration and firm size. The model in this paper has these characteristics. The GE structure adds the benefit of making explicit the endogenous determination of demand and saving, and the fact that firms compete not only for sales, but also for resources.
} 
describe market structure and simplifies the analysis. The condition that the present value of profits, net of $R \& D$ costs, equals sunk entry costs determines the dynamics of the number of firms. Once in the market, firms engage in price competition and establish in-house R\&D facilities to reduce costs, offer lower prices, and gain market share. ${ }^{3}$ Technological progress and market structure are jointly determined in a two-dimensional representation of the growth path of the economy. Technological progress is measured by the average rate of cost reduction. Market structure is measured by the number of firms.

In Section 2, I present preferences and technology. In Section 3, I construct the industry Nash equilibrium (NE) with free entry. I then impose labor and capital market clearing and construct the GE of the economy. In Section 4, I establish the properties of the steady state of this equilibrium and discuss the main results of the paper. In Section 5, I study the welfare implications of these results.

In steady state, the number of firms is endogenous and jointly determined with the rate of growth. R\&D and entry decisions are interdependent in the goods, capital, and labor markets. Three forces drive my results. First, dynamic increasing returns in $\mathrm{R} \& \mathrm{D}$ are internal to the firm and the rate of cost reduction depends on the scale of the R\&D program of the individual firm. In order to take advantage of increasing returns, $R \& D$ resources must be concentrated on a small number of firms. Second, R\&D is a component of a firm's total fixed costs and is negatively related to the returns to entry. ${ }^{4}$ In fast growing economies, high R\&D spending results in a small number of firms. Third, production and $R \& D$ compete for labor. Since employment in production increases with the number of firms, a large number of firms reduces employment in R\&D and, therefore, growth. These forces capture the interdependence of market structure and growth and generate a fundamental trade-off between the number of firms

\footnotetext{
${ }^{3}$ Thompson and Waldo (1994) propose the notion of 'trustified capitalism' to describe markets where 'innovating firms capture market share from their rivals but do not drive them out of business' (p. 445). They quote Schumpeter (1928) who distinguished between competitive and trustified capitalism. Competitive capitalism, they argue, corresponds to models of 'creative destruction' (e.g., Aghion and Howitt 1992; Grossman and Helpman, 1991, Chapter 4), where innovations are introduced by new firms who capture the entire market but whose tenure as monopolists is only temporary. Trustified capitalism corresponds to models where innovations are brought to the market by established firms who capture some, but not all, of their rivals' business (pp. 446-447). Note that quality-improvement and cost-reduction are formally equivalent when one considers the quality of the good as determining the cost at which the good delivers its services (Spence, 1984; Tirole, 1988). Thus, although I focus on cost-reduction, I can rewrite the model in terms of quality-improvement and interpret it as a smooth version (quality being a continuous variable) of the quality-ladder model with an endogenous variety of goods (number of firms).

${ }^{4} \mathrm{R} \& \mathrm{D}$ expenditure is one component of a firm's total cost and is endogenously determined in the industry equilibrium. This cost is sunk and borne at each moment in time. Formally, it is identical to a fixed production cost. Entrants anticipate that they must pay this cost in equilibrium. Therefore, the R\&D cost can also be identified as an endogenous entry cost (Sutton, 1991).
} 
and growth. Two aspects of this trade-off capture the main insight of the model. In this oligopolistic economy each firm produces one good and households have love-of-variety preferences. It follows that the trade-off between the number of firms and growth is also a trade-off between competition and growth, between firms' market power and R\&D spending decisions, and between variety and growth, between the variety of consumption goods and the rate of growth of consumption of each good.

This property provides the central insight of the paper. The positive and normative results depend on the interdependence of market structure, firms' exercise of market power, and growth. The crucial link in this chain is firms' exercise of market power which is endogenous and depends on market structure. The inclusion of this link distinguishes this paper from the current literature. On the positive side, the most interesting result concerns the role of population size: in this model, the scale effect is positive but vanishes asymptotically. This result is important. It suggests that if the labor force grows at a constant rate, the oligopolistic economy converges to monopolistic competition where the scale effect is always zero. The number of firms then grows at the same rate as the labor force while the rate of growth does not change. It is possible to introduce population growth in this class of models without the counterfactual prediction of explosive growth rates. This property suggests an important direction for future research.

On the normative side, the main result is that the market provides too much variety and too little growth. This result does not depend on the existence of technological externalities. In addition, in this one-sector economy oligopolistic pricing does not give rise to distortions across industries because firms charge identical markups and all goods command identical prices. The model identifies a new distortion. Specifically, oligopolistic firms face a price elasticity of demand that is lower than the elasticity of product substitution. As a consequence, the private rate of return to R\&D is too low and firms spend too little on R\&D. Since R\&D is a fixed cost, this implies that the rate of return to entry is too high and that too many firms enter the market. The Pareto inefficiency of this economy, therefore, has two, intertwined aspects: insufficient growth and excessive entry. The magnitude of this distortion is endogenous and depends on the number of firms. As this becomes very large, the market equilibrium approaches asymptotically the social optimum.

\section{The model: Preferences and technology}

I consider a closed economy with a fixed population, L, of identical individuals who supply labor services and consumption loans in competitive labor and capital markets. Each individual is endowed with one unit of labor that he supplies inelastically. 


\subsection{Preferences}

The typical consumer maximizes lifetime utility

$$
U(t)=\int_{t}^{\infty} \mathrm{e}^{-\rho(\tau-t)} \log C(\tau) \mathrm{d} \tau,
$$

subject to the intertemporal budget constraint that the present discounted value of expenditure cannot be greater than the present discounted value of labor and dividend income plus initial wealth,

$$
\int_{t}^{\infty} R(\tau) E(\tau) \mathrm{d} \tau \leq \int_{t}^{\infty} R(\tau)[W(\tau)+D(\tau)] \mathrm{d} \tau+B(t),
$$

where $\rho>0$ is the individual discount rate, $R(\tau) \equiv e^{-\int_{t}^{t} r(s) \mathrm{d} s}$ is the cumulative discount factor, $E$ is per capita expenditure, $B$ is assets holding, $W$ is the wage rate, and $D$ is dividends (profits are distributed in equal shares to consumers). In the following analysis, I take the wage rate as the numeraire.

Individuals have symmetric preferences $C(\tau)$ over a range of differentiated goods

$$
C=\left[\sum_{i=1}^{N} C_{i}^{(\varepsilon-1) / \varepsilon}\right]^{\varepsilon /(\varepsilon-1)},
$$

where $\varepsilon>1$ is the elasticity of product substitution, $C_{i}$ is the consumer's purchase of each differentiated good, and $N>1$ is the number of goods (the number of active firms).

The solution for the optimal expenditure plan is well known. Consumers set

$$
\dot{E} / E=r-\rho
$$

and taking as given this time-path of expenditure maximize Eq. (2) subject to $E=\sum_{i=1}^{N} P_{i} C_{i}$. This yields the instantaneous demand schedule for the firm

$$
X_{i}=L E \cdot\left[\frac{P_{i}^{-\varepsilon}}{\sum_{j=1}^{N} P_{j}^{1-\varepsilon}}\right]
$$

where $X_{i}=L \cdot C_{i}$ is total output since there are $L$ identical consumers.

\subsection{Technology}

Each firm produces output with the technology

$$
L_{X_{i}}=h\left(Z_{i}\right) \cdot X_{i},
$$

where $X_{i}$ is output and $L_{X_{i}}$ is labor employment. The firm runs in-house R\&D facilities to produce, over time, a continuous flow of cost-reducing innovations to reduce marginal costs, $h\left(Z_{i}\right) \equiv Z_{i}^{-\theta}$. To keep the algebra simple, I assume 
a constant elasticity of cost reduction, $0<\theta<1$. The $R \& D$ technology is

$$
\dot{Z}_{i}=L_{Z i}^{\gamma} \cdot Z_{i}
$$

where $\dot{Z}_{i}$ is the flow of innovations generated by an R\&D project employing $L_{Z i}$ units of labor and $Z_{\mathrm{i}}$ is the firm's stock of knowledge. The R\&D technology exhibits increasing returns to scale to knowledge and labor, decreasing returns to scale to labor, and constant returns to scale to knowledge, the accumulated factor. This ensures that steady-state constant growth is feasible.

This setup emphasizes local, incremental technological progress. The focus is on those costly learning activities, not necessarily formal R\&D, that firms undertake to improve labor productivity (see, e.g., Dosi, 1988; Malerba, 1992). In addition to innovations, these activities generate knowledge that raises the productivity of future R\&D. ${ }^{5}$ This knowledge is specific to the product line, that is, it is product- and process-specific. I refer to it as firm-specific since in this model each firm produces one product. The firm that undertakes R\&D in-house has two advantages over outsiders: (i) privileged information about the product and the production process, i.e., outsiders who do not operate the process cannot improve it as effectively as the firm that does; (ii) dynamic learning economies in $R \& D$, i.e., the productivity of $R \& D$ improves with the cumulated stock of knowledge. Firms undertake R\&D in-house in order to internalize advantages due to proximity to the production line and firm-specific learning economies.

\section{Industry equilibrium and aggregate dynamics}

Firms face identical production and R\&D technologies and demand schedules. They behave non-cooperatively and maximize the value of their shares. Incumbents take as given the time-path of entry. Entrants take as given the time-paths of prices and R\&D that they expect to prevail in the post-entry equilibrium. Incumbents and entrants have rational expectations and correctly anticipate these time-paths. In this Section, I construct the equilibrium with free entry and exit for the manufacturing sector. I then impose labor and capital market clearing to determine the GE of the economy. Output market clearing results from the price-setting behavior of firms. I restrict the analysis to symmetric equilibria in order to focus on the aggregate properties of the model.

\footnotetext{
${ }^{5}$ Innovations are codified information (e.g., blueprints, instruction manuals) that the labor force applies in production operations. Knowledge is a product of the firm's innovation effort and is largely tacit. If one thinks of $R \& D$ as problem-solving, innovations are the solutions to specific production problems that firms face and knowledge is the experience or learning accumulated by the problem-solving team. They both are firm-specific: they are non-rival at the firm level but not at the industry level.
} 


\subsection{Definition of industry equilibrium}

The typical firm maximizes the present discounted value of net cash flow,

$$
V_{i}=\int_{t}^{\infty} R(\tau) \Pi_{i}(\tau) \mathrm{d} \tau
$$

Using the cost function (1), instantaneous profits, $\Pi_{i}(\tau)$, are

$$
\Pi_{i}=\left[P_{i}-h\left(Z_{i}\right)\right] X_{i}-L_{Z_{i}},
$$

where $L_{Z i}$ is $\mathrm{R} \& \mathrm{D}$ expenditure. With perfect foresight, $V_{i}$ is the stock market value of the firm, the price of the ownership share of an equity holder.

I consider a symmetric Nash equilibrium (NE) in open loop strategies. Let $a_{i}=\left[P_{i}(\tau), L_{Z_{i}}(\tau)\right]$ for $\tau \geq t$ be firm i's strategy, where $P_{i}(\tau)$ and $L_{Z i}(\tau)$ are the time-paths of price and $R \& D$. This price and $R \& D$ strategy induces time-paths of production, sales, innovation, and knowledge accumulation. At time $t$, firms commit to time-paths of price and R\&D, taking as given the time-path of the number of firms. Similarly, entrants take as given the incumbents' time-paths of price and R\&D. Let $V_{i}\left[N, A_{N}\right]$ be the value of firm $i$ when $N$ firms are in the market and they play strategies $A_{N}=\left[a_{1}, \ldots, a_{N}\right]$. Let $\beta>0$ be the cost of entry in units of labor (to be further defined below). At time $t,\left[N, A_{N}\right]$ is an equilibrium with free entry and free exit if for all $i$

$$
V_{i}\left[N, A_{N}\right] \geq V_{i}\left[N, A_{N}^{\prime}\right] \geq 0
$$

and for all $N>1$

$$
V_{i}\left[N+1, A_{N+1}\right] \leq \beta,
$$

where $\left[A_{N}^{\prime}\right]$ denotes strategies when firm i deviates from the optimal time-path of price and investment while the other firms do not deviate (see, e.g., Dasgupta and Stiglitz, 1980). Condition (9) requires that the active firm maximizes the present value of net cash flow, taking as given the other firms' strategies, and that this maximized value be non-negative. The latter inequality is the free-exit condition since the scrap value of the active firm, the opportunity cost of incumbency, is zero. Eq. (10) is the free-entry condition that the value of entrants, net of sunk entry costs, be non-positive.

\subsection{Pricing and $R \& D$}

The intertemporal problem of the typical firm is to maximize Eq. (7), subject to the production and R\&D technologies Eqs. (5) and (6), the demand schedule Eq. (4), $Z_{i}(t)=Z>0$ (the initial knowledge stock is given and equal for all firms), $Z_{j}(\tau)$ for $\tau \geq t$ and $j \neq i$ (the firm takes as given the innovation paths of 
rivals), $\dot{Z}_{i}(\tau) \geq 0$ for $\tau \geq t$ (innovation is irreversible). The current value hamiltonian $(\mathrm{CVH})$ for this problem is

$$
\mathrm{CVH}_{i}=\left[P_{i}-h\left(Z_{i}\right)\right] \cdot X_{i}-L_{z i}+q_{i} \cdot L_{Z i}^{\gamma} \cdot Z_{i},
$$

where the costate variable, $q_{i}$, is the value of the innovation. The firm's knowledge stock, $Z_{i}$, is the state variable and $\mathrm{R} \& \mathrm{D}$ investment, $L_{Z i}$, and the product's price, $P_{i}$, are the control variables.

The first-order conditions are given by equality between marginal revenue from the innovation and its marginal cost, $1=q_{i} \cdot \gamma L_{Z i}^{\gamma-1} \cdot Z_{i}$, the transversality condition, $\lim _{t \rightarrow \infty} R(t) \cdot q_{i}(t) \cdot Z_{i}(t)=0$, the constraint on the state variable, $\dot{Z}_{i}=L_{Z i}^{\gamma} \cdot Z_{i}$, and a differential equation in the costate variable

$$
r=\frac{\dot{q}_{1}}{\dot{q}_{i}}-\frac{h^{\prime}\left(z_{i}\right) \cdot X_{i}}{q_{i}}+L_{Z i}^{\gamma},
$$

that defines the rate of return to $R \& D$ as the ratio between revenues from the innovation and its shadow price. The optimal Bertrand-Nash price strategy is

$$
P_{i} / h\left(Z_{i}\right)=\eta_{i} /\left(\eta_{i}-1\right),
$$

where $\eta_{i}=\varepsilon-(\varepsilon-1) \cdot S_{i}>1$ is the 'perceived' price elasticity of demand and $S_{i} \equiv P_{i}^{1-\varepsilon} / \sum_{j=1}^{N} P_{j}^{1-\varepsilon}$ is the market share, defined as the value of the firm's output divided by the value of industry output; multiply Eq. (4) by $P_{i}$ to see this. A Bertrand-Nash equilibrium exists only if the price elasticity of demand is larger than one. In symmetric equilibrium, this requires $N>1$.

The condition that the innovation's marginal cost equal its marginal benefit can be rearranged to get the firm's policy function

$$
L_{Z i}=\left[\gamma q_{i} Z_{i}\right]^{1 /(1-\gamma)} .
$$

Substituting the price strategy (13) into the demand schedule (4) and substituting the result into Eq. (12), one can write

$$
r=\frac{\dot{q}_{i}}{q_{i}}+\frac{L E \theta\left(\eta_{i}-1\right) S_{i}}{\eta_{i} q_{i} Z_{i}}+L_{Z i}^{\gamma}
$$

Similarly, Eq. (8) can be written

$$
\Pi_{i}=\frac{\mathrm{LES}_{i}}{\eta_{i}}-L_{Z i} .
$$

At a moment in time, profits are given by total cash flow minus R\&D costs.

The NE of this game is given by the first order conditions for all active firms. Firms start out with the same knowledge stock. Since they obey identical 
differential equations with identical boundary conditions, they accumulate knowledge at the same rate and the NE is symmetric at all times. ${ }^{6}$

In symmetric equilibrium the rate of return to $R \& D$ in Eq. (15) becomes

$$
r_{\mathrm{R} \& \mathrm{D}}=\frac{\dot{q}}{q}+\frac{L E \theta(\varepsilon-1)(N-1)}{\varepsilon(N-1)+1} \frac{1}{q Z}+\left(\frac{L_{Z}}{N}\right)^{\gamma},
$$

where $L_{Z}$ is aggregate employment in R\&D ("aggregate $\mathrm{R} \& \mathrm{D}$ "). The rate of return to $R \& D$ has three components: (i) the appreciation (depreciation) in the value of knowledge; (ii) the effect of the innovation on cash flow (this is the cost-reducing effect of knowledge accumulation) divided by its replacement cost; (iii) dynamic learning economies in $\mathrm{R} \& \mathrm{D}$.

The effect of the cost reduction on cash flow can be further decomposed into two terms: (i) gross profits earned on a given market share, the term $L E /[\varepsilon(N-1)+1]$; and (ii) the increase in market share achieved by the R\&D project, the term $\theta(\varepsilon-1)(N-1) / N$. I label these the gross-profit and the business-stealing effect, respectively. The gross-profit effect is decreasing in the number of firms, $N$, because the market share and the markup are lower the larger is $N$. The business-stealing effect is increasing in the number of firms because the total market share that the firm can steal is given by the rivals' market share, $(N-1) / N$. As a result, the rate of return to $R \& D$ is hump-shaped in the number of firms. This shape captures the intuitive fact that the businessstealing effect, which depends on the rivals' market share, and the gross-profit effect, which depends on the firm's market share, work in opposite directions. When there are few firms and the firm's market share is large, the business-stealing effect dominates and the returns to R\&D increase with the number of firms. When there are many firms and the firm's market share is small, the gross-profit effect dominates and the returns to R\&D fall with the number of firms.

\subsection{Entry and exit}

The characteristics of the free-entry equilibrium depend on the assumptions one makes about the diffusion and circulation of knowledge across firms. With

\footnotetext{
${ }^{6}$ The properties of this class of capital accumulation, differential games have been established only in few cases (see, e.g., Fershtman and Mueller 1984). For a general discussion, see Tirole (1988, Chapter 8), and Fudenberg and Tirole (1991, Chapter 13). The NE of the knowledge accumulation game in the text is given by the first order conditions from the firms' maximization problems that yield a $2 N$-dimensional system of differential equations describing the industry transitional dynamics for a given number of firms. Since these micro dynamics are not crucial to the aggregate analysis of this paper, I assume that firms start out with the same stock of knowledge. This assumption and the characterization of entry discussed below yield that the industry is always in symmetric equilibrium.
} 
entry, a symmetric equilibrium is possible only under restrictive conditions. It is, however, easy to analyze and conveys clearly the insight of the model. Hence, I focus on a symmetric equilibrium and justify it by assuming that knowledge diffuses as workers move from one firm to the other. Since incumbents have been accumulating knowledge at equal rates, all workers have the same level of expertise. By hiring workers from incumbents, new goods can be produced with the state-of-the-art technology provided entrepreneurs are willing to sink the labor cost of adapting the existing technology to the new goods. This implies an implicit spillover from incumbents to entrants. Starting up a new firm is costly because a new organization must be created and problems specific to the production process of the new good must be solved.

The entrant devotes $\beta$ units of labor to set up operations. The initial knowledge is equal to the incumbents' average knowledge, $Z_{e}(t)=Z(t)$, since this is the state of the art in a symmetric equilibrium. Entry $\operatorname{costs} \beta$ and produces value $V_{i}$. The case $V_{i}>\beta$ yields an unbounded demand for labor in entry and is ruled out. A free-entry equilibrium requires $V_{i} \leq \beta$, with equality whenever $\dot{N}>0$ and strict inequality whenever $\dot{N}=0 .{ }^{7}$ This condition implies that in an equilibrium with entry the exit condition is not binding. This is intuitive: sunk, entry costs lead to different threshold values for entry and exit.

Taking logs and time-derivatives of Eq. (7) and rearranging terms yields

$$
r=\frac{\Pi_{i}}{V_{i}}+\frac{\dot{V}_{i}}{V_{i}}
$$

which is a perfect-foresight, no-arbitrage condition for the equilibrium of the capital market. It requires that the rate of return to firm ownership equal the rate of return to a riskless loan of size $V_{i}$. The rate of return to firm ownership is the ratio between profits and the firm's stock market value plus the capital gain (loss) from the stock appreciation (depreciation).

In an equilibrium with entry, $V_{i}=\beta$ implies $\dot{V}_{i}=0$. Eq. (18) yields the instantaneous free-entry condition, $r=\Pi_{i} / \beta$. In symmetric equilibrium, the rate of return to entry becomes

$$
r_{\text {entry }}=\frac{1}{\beta}\left[\frac{L E}{\varepsilon(N-1)+1}-\frac{L_{Z}}{N}\right],
$$

where $L_{Z}$ is aggregate $\mathrm{R} \& \mathrm{D}$. The condition $V_{i}=\beta$ implies that in an equilibrium with entry, the rate of return to entry is equal to the rate of return to firm ownership. The former is equal to the ratio between net revenues and entry

\footnotetext{
${ }^{7}$ The reader should notice the change of notation. The assumptions discussed in Section 2 and the definition of equilibrium given in Section 3 treat the number of firms, $N$, as discrete. It is, however, analytically convenient to treat it as a continuous variable in the following analysis of the model.
} 
costs. Alternatively, if profits are distributed to shareholders, the rate of return to firm ownership is equal to the ratio between dividends and the value of the firm.

Eq. (19) captures two interesting effects: (i) the gross-profit effect, the term $L E /[\varepsilon(N-1)+1]$; and (ii) the $R \& D$-cost effect, the term $L_{Z} / N$. In equilibrium, gross profits equal entry costs. These have two components: $R \& D$ expenditure and interest payments on exogenous entry costs, $r \beta$. The former identifies the costs that the entrant pays to keep the pace of progress of the industry. The latter identifies the costs that he pays to write off the initial start-up investment. The R\&D-cost effect captures the fact that in fast growing industries, firms spend heavily on R\&D and the market accommodates fewer firms in free-entry equilibrium. Therefore, there is a negative effect of growth on the rate of return to entry. This generates a feed-back effect from growth to market structure that interacts with the direct effect from market structure on growth discussed above.

\subsection{Growth}

It is now useful to shift the focus of the discussion from $R \& D$ to growth. Let $\mathrm{g}$ be the average rate of cost reduction, the rate of growth of labor productivity in this model ("growth"). The R\&D technology (Eq. (6)) can be rewritten

$$
g \equiv \theta\left(L_{Z} / N\right)^{\gamma}
$$

This equation contains one of the key ingredients of the model. Given aggregate $\mathrm{R} \& \mathrm{D}, L_{Z}$, growth, $g$, is decreasing in the number of firms, $N$. This property captures the dispersion effect. In this model, dynamic increasing returns are internal to the firm and the rate of cost reduction depends on the scale of the $R \& D$ program of the individual firm. Growth, accordingly, depends on average R\&D, not aggregate $\mathrm{R} \& \mathrm{D}$. This effect, in a sense, is 'assumed' in the R\&D technology (Eq. (6)) in order to capture the basic empirical fact that $R \& D$ is undertaken by individual firms. The main empirical implication of this assumption is that one should not look at aggregate R\&D but at the entire distribution of R\&D efforts across firms and then recover growth by taking some appropriate average. In a stylized model like the one discussed here, it is analytically convenient to focus on aggregate variables. This procedure hides some of the micro details but makes the analysis of the macro aspects of the model very simple. In this perspective, the key to Eq. (20) is that growth is determined by two endogenous variables: aggregate $R \& D$ and the number of firms. The full effect of the number of firms on growth, therefore, depends on two effects: (i) the dispersion effect, just discussed; and (ii) the rivalry effect, the effect of an increase in competition on aggregate $\mathrm{R} \& \mathrm{D}$. Recall, in addition, that there is a feed-back from $\mathrm{R} \& \mathrm{D}$ to the number of firms through the R\&D-cost effect. 


\subsection{General equilibrium and aggregate dynamics}

To determine the aggregate dynamics of the economy, I now impose two conditions: labor market clearing and equality between the rate of return to investment and the rate of return to saving. Substituting the price strategy (13) into the cost function (5), using the demand schedule (4), and aggregating over firms, one obtains employment in production ("aggregate production") as

$$
L_{X}=\frac{L E(\varepsilon-1)(N-1)}{\varepsilon(N-1)+1} .
$$

Labor market clearing requires $L=L_{X}+L_{Z}+L_{N}$, where $L_{N}=\beta \dot{N}$ is employment in entry ("entry"). In an equilibrium with entry, employment in all activities must be positive and $L>L_{X}+L_{Z}$ must hold. The equation $L>L_{X}+L_{Z}$ identifies the border between two regions, one where entry is profitable and one where entry is not profitable. These are the entry and the blockaded-entry region, respectively. I present here only the equations for the entry region. Using Eqs. (20) and (21), one can write the labor market clearing condition as

$$
\beta \cdot \frac{\dot{N}}{N}=\frac{L}{N}-\frac{L E(\varepsilon-1)(N-1)}{\varepsilon(N-1)+1}-\left(\frac{g}{\theta}\right)^{1 / \gamma},
$$

where the reader should recall that the wage rate is the numeraire.

Consider now the capital market. Using Eq. (20) and the policy function (14), the rate of return to $R \& D$ in Eq. (17) can be written

$$
r_{\mathrm{R} \& \mathrm{D}}=\frac{1-\gamma}{\gamma} \cdot \frac{\dot{g}}{g}+\frac{\operatorname{LE\gamma } \theta(\varepsilon-1)(N-1)}{\varepsilon(N-1)+1}\left(\frac{\theta}{g}\right)^{(1-\gamma) / \gamma} .
$$

Similarly, the rate of return to entry in Eq. (19) can be written

$$
r_{\text {entry }}=\frac{1}{\beta}\left[\frac{L E}{\varepsilon(N-1)+1}-\left(\frac{g}{\theta}\right)^{1 / \gamma}\right] .
$$

These are the returns to two types of investment: R\&D and start-up of new firms. No-arbitrage requires that the two rates of return be equal. This yields

$$
\frac{1-\gamma}{\gamma} \cdot \frac{\dot{g}}{g}=\frac{1}{\beta}\left[\frac{L E}{\varepsilon(N-1)+1}-\left(\frac{g}{\theta}\right)^{1 / \gamma}\right]-\frac{L E \gamma \theta(\varepsilon-1)(N-1)}{\varepsilon(N-1)+1}\left(\frac{\theta}{g}\right)^{(1-\gamma) / \gamma} .
$$

Since this equation results from equalizing the returns to R\&D and entry, there is a unique rate of return to investment. The next step is to equalize this rate of return to investment to the rate of return to savings in order to ensure capital 
market clearing. Substituting the savings policy Eq. (3) into Eq. (24) yields

$$
\frac{\dot{E}}{E}=\frac{1}{\beta}\left[\frac{L E}{\varepsilon(N-1)+1}-\left(\frac{g}{\theta}\right)^{1 / \gamma}\right]-\rho .
$$

The GE of the economy is thus described by a system of three differential equations in $(N, E, g)$ space. To discuss the main results of the paper, it is sufficient to consider the steady state of this system. A technical Appendix available on request provides details on transitional dynamics.

\section{Growth and market structure in steady state}

In this section, I discuss the main results of the paper. I first examine the interaction of R\&D and entry in isolation. This exercise provides some nice intuition on the forces at work. I then consider the full GE of the economy.

\subsection{Free-entry equilibrium}

Suppose a steady state where all endogenous variables, $g, N$ and $E$, are constant. Consider Fig. 1, where I represent no-arbitrage between R\&D and entry as the intersection of Eqs. (23) and (24) in $(g, r)$ space. There are two intersections, points $\mathrm{A}$ and $\mathrm{B}$. Point $\mathrm{A}$ is a stable Nash equilibrium for the capital market: to its left, the rate of return to $R \& D$ is higher than the rate of return to entry, funds are reallocated from entry to $R \& D$, and the market moves

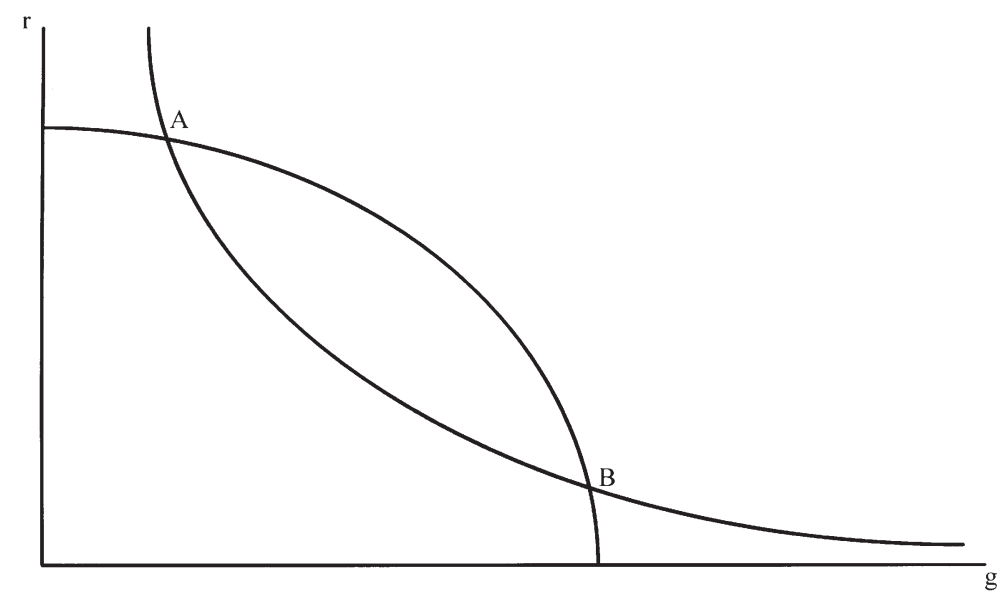

Fig. 1. Nash eqilibrium of the capital market. 
back to equilibrium; to its right, the rate of return to entry is higher than the rate of return to $\mathrm{R} \& \mathrm{D}$, funds are reallocated from $\mathrm{R} \& \mathrm{D}$ to entry, and the market moves back to equilibrium. Stability obtains because Eq. (23) is locally steeper than Eq. (24). It follows that point B is an unstable Nash equilibrium and can be ruled out.

The stable equilibrium is described by

$$
\frac{\operatorname{LE\gamma } \theta(\varepsilon-1)(N-1)}{\varepsilon(N-1)+1}\left(\frac{\theta}{g}\right)^{(1-\gamma) / \gamma}=\frac{1}{\beta}\left[\frac{L E}{\varepsilon(N-1)+1}-\left(\frac{g}{\theta}\right)^{1 / \gamma}\right] .
$$

This locus yields growth, $g$, as an implicit function, hump-shaped in the number of firms, $N$, and increasing in aggregate demand, $L E$. This result is interesting and is worth emphasizing.

Result 1. When the returns to $R \& D$ and entry are equalized, growth is humpshaped in the number of firms and increasing in the size of the market.

It should be stressed that this is a partial equilibrium result, in the sense that Eq. (27) takes the number of firms and aggregate demand as given and ignores the GE constraints. The forces that explain it, however, play a central role in this model. It is thus useful to examine them in isolation.

Recall that Eq. (20) states that growth is determined by the interaction of aggregate $\mathrm{R} \& \mathrm{D}, L_{Z}$, and the number of firms, $N$. In particular, an increase in the number of firms has two effects on growth. Holding constant aggregate R\&D, it reduces average $R \& D$ and, therefore, growth. This is the dispersion effect. In addition, an increase in the number of firms raises aggregate $R \& D$ (this can be shown by rewriting Eq. (27) in terms of aggregate $R \& D$ ). This is the rivalry effect and is the outcome of the interaction between the gross-profit and the businessstealing effects discussed above. Recall that the business-stealing effect is humpshaped in the number of firms. When the number of firms is small, an increase in $N$ raises the rate of return to $\mathrm{R} \& \mathrm{D}$ and lowers the rate of return to entry. Restoring equilibrium requires an increase in growth. When the number of firms is large, an increase in $N$ lowers both rates of returns and equilibrium is restored by a reduction in growth. As the number of firms becomes very large growth converges to zero. The intuition here is that the dispersion effect eventually dominates the rivalry effect and the increase in aggregate $R \& D$ generated by a larger number of firms does not compensate for the dispersion of R\&D resources across firms.

The positive effect on growth of an increase in aggregate demand, $L E$, is the standard scale effect. A larger market attracts higher R\&D spending. This property is nicely captured by the gross-profit effect, which is the main channel of scale effects in this model. Since R\&D is firm-specific, the returns to a specific innovation are determined by the scale of activity of the firm that develops and 
applies it, not by the scale of activity of the whole economy. Thus, whether or not one observes scale effects in this economy depends on how changes in the scale of the economy translate into changes in the size of the firm.

\subsection{General equilibrium}

It is now useful to eliminate spending per capita, $E$, and reduce the threedimensional system (22), (25) and (26) to a two-dimensional system in the number of firms, $N$, and the rate of growth, $g$. I begin by constructing the locus (FF) of the full-employment, value-maximizing labor allocations. This locus describes equilibria where entry is blockaded and the number of firms does not adjust endogenously to changes in parameters. (Thus, it describes the equilibrium of a model with an exogenous number of firms.) Consider the rate of return to R\&D in Eq. (23). In steady state, this must be equal to the discount rate, $\rho$. Substituting the resulting expression into Eq. (22) yields

$$
\frac{L}{N}=\frac{\rho}{\gamma \theta}\left(\frac{g}{\theta}\right)^{(1-\gamma) / \gamma}+\left(\frac{g}{\theta}\right)^{1 / \gamma} .
$$

Next, I construct the locus (NN) of the no-arbitrage, value-maximizing labor allocations. This locus describes equilibria where the number of firms adjusts endogenously to changes in parameters. Setting the rates of return to R\&D and entry equal to the discount rate, $\rho$, and substituting Eq. (23) into Eq. (24) yields

$$
\beta=\frac{N}{\gamma \theta(\varepsilon-1)(N-1)}\left(\frac{g}{\theta}\right)^{(1-\gamma) / \gamma}-\frac{1}{\rho}\left(\frac{g}{\theta}\right)^{1 / \gamma} .
$$

This implicit equation, which is the equivalent of Eq. (27) derived above, has two solutions for growth, $g$, as a function of the number of firms, $N$. Recall that one of them is an unstable $N E$ for the capital market and is ruled out.

The FF and NN loci, depicted in Fig. 2, capture the interdependence of market structure and $\mathrm{R} \& \mathrm{D}$ decisions that generates a fundamental trade-off between the number of firms and growth. The FF locus identifies it in the labor market. The NN locus identifies it in the capital market. It is useful to highlight two aspects of this trade-off that capture the main insight of this model. Recall that this paper describes an oligopolistic economy where each firm produces one good and where households have love-of-variety preferences. It follows that the trade-off between the number of firms and growth is indeed a trade-off between variety and growth, between the variety of consumption goods and the rate of growth of consumption of each good. This trade-off plays a crucial role in the next Section where I study the welfare implications of the model. Moreover, the price strategy (13) implies that markups over marginal costs are endogenous and depend on the number of firms. It follows that the trade-off between the number of firms and growth is also a trade-off between competition and growth, between 


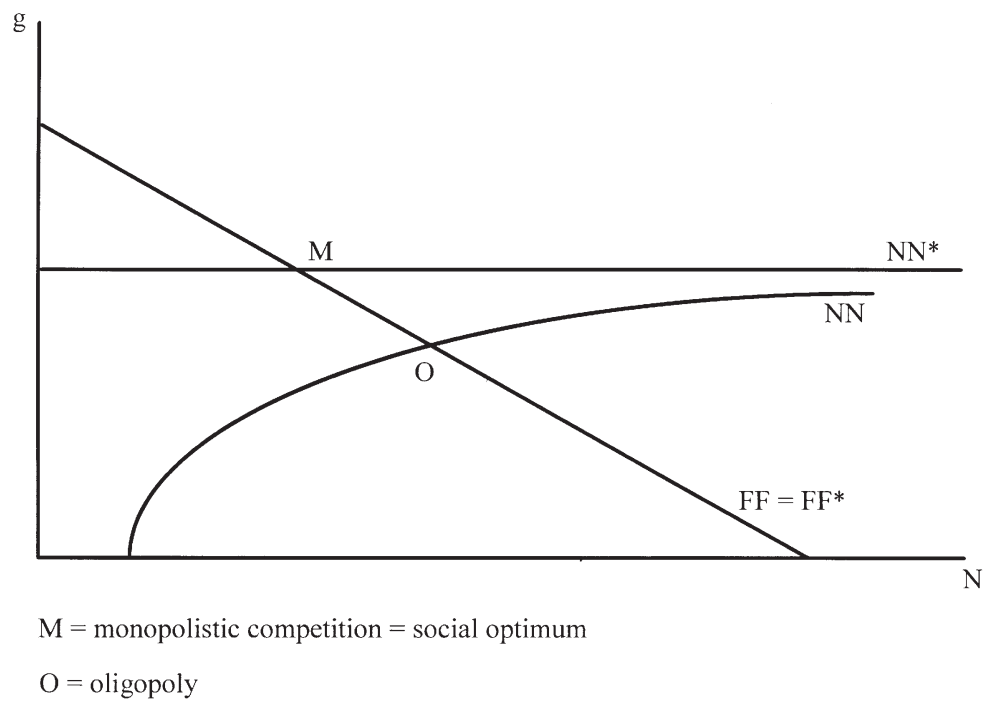

Fig. 2. Steady-state growth and market structure.

the market power of firms and their R\&D spending decisions. This trade-off provides the central insight of the paper. In particular, both the positive and the normative implications of the model depend crucially on the interaction between market structure, firms' exercise of market power, and growth. It is worth stressing this point. In this model, firms' exercise of market power is endogenous because firms face a price elasticity of demand that is decreasing in the market share,

$$
\eta=\varepsilon-(\varepsilon-1) \frac{1}{N}
$$

If one assumes that firms are atomistic, one approximates the price elasticity of demand with the elasticity of product substitution, $\eta=\varepsilon$, and markups become exogenous. By reducing the Bertrand oligopoly model to one of monopolistic competition, this assumption shuts down one of the most important feed-backs of the model. The results, then, are radically different.

To analyze the trade-off between the number of firms and growth, it is useful to rewrite Eq. (23) as

$$
L_{Z}=\left(\frac{L_{X} \gamma \theta}{\rho}\right)^{1-\gamma} N^{\gamma}
$$

This equation states that to keep the rate of return to R\&D equal to the discount rate, $\rho$, aggregate $\mathrm{R} \& \mathrm{D}$ must be an increasing function of aggregate production 
(scale effect) and the number of firms (rivalry effect). Similarly, the free-entry equilibrium (27) can be rewritten

$$
\frac{L_{X} \gamma \theta \beta}{N}=\left(\frac{L_{Z}}{N}\right)^{1-\gamma}\left[\frac{L_{X} N}{(\varepsilon-1)(N-1)}-\frac{L_{Z}}{N}\right] .
$$

This equation state that to equalize the rates of return to R\&D and entry, aggregate R\&D must be an increasing function of aggregate production (scale effect) and the number of firms (rivalry effect).

Suppose now an increase in the number of firms. Eq. (31) states that aggregate $R \& D$ increases with the number of firms (rivalry effect). The labor market clearing condition then implies a fall in aggregate production which feeds-back negatively on aggregate $R \& D$ (scale effect). As a result of these forces, aggregate $\mathrm{R} \& \mathrm{D}$ increases (this can be seen by substituting the labor market clearing condition into Eq. (31) and checking the comparative statics for the resulting implicit function) but not by an amount sufficient to offset the fall in average R\&D caused by the larger number of firms (dispersion effect). This mechanism explains the negative slope of the FF locus. The slope of the NN locus is explained as follows. Recall that Eq. (32) results from equalization of the rates of return to R\&D and entry. Two additional effects change crucially the interaction between $R \& D$ and entry with respect to the partial equilibrium analysis of the previous section. In steady state, the rate of return is pinned down by the discount rate, $\rho$. In addition, aggregate production is endogenous and cannot be held constant. Suppose then an increase in the number of firms. Eq. (32) states that, holding constant aggregate production, aggregate $R \& D$ rises in response to an increase in the number of firms (rivalry effect). Eq. (31) states that, holding constant aggregate $\mathrm{R} \& \mathrm{D}$, the increase in the number of firms requires a fall in aggregate production in order to keep the rate of return to $R \& D$ equal to the discount rate. This fall in aggregate production feeds back negatively on aggregate $R \& D$ (scale effect). The NN locus is upward sloping because the increase in aggregate $R \& D$ that results from these forces is more than sufficient to offset the fall in average R\&D caused by the larger number of firms (dispersion effect). Asymptotically, these effects balance and the NN locus becomes flat. An increase in the number of firms that reduces average R\&D is matched by an increase in aggregate $R \& D$. When the number of firms is very large, growth converges to a constant given by the solution to

$$
\beta=\frac{1}{\gamma \theta(\varepsilon-1)}\left(\frac{g}{\theta}\right)^{(1-\gamma) / \gamma}-\frac{1}{\rho}\left(\frac{g}{\theta}\right)^{1 / \gamma} .
$$

This is the NN locus that arises in a model of monopolistic competition. Moreover, Eq. (30) implies that the Bertrand oligopoly model converges to monopolistic competition as the number of firms becomes large. 
The intersection of the FF and NN loci is the free-entry steady state. A simple comparative statics exercise yields the result.

Result 2. In the free-entry steady state, growth is increasing in $L, \beta, \theta, \gamma$ and $\varepsilon$, and decreasing in $\rho$; the number of firms is increasing in $L$, and decreasing in $\beta$ and $\varepsilon$, while the effects of $\theta, \gamma, \rho$ are ambiguous.

The interdependence of market structure and growth produces a very interesting new result. An increase in population, $L$, implies that the resource base of the economy is larger. One expects that both aggregate R\&D and aggregate production rise. Suppose that all the extra labor force initially goes into production. This raises aggregate $R \& D$ in Eq. (32) and, as a consequence, Eq. (31) requires the number of firms to rise in order to keep the rate of return to $\mathrm{R} \& \mathrm{D}$ equal to the discount rate. Although both these changes raise aggregate $R \& D$, via the scale and rivalry effects, the dispersion effect eventually offsets the increase in aggregate $\mathrm{R} \& \mathrm{D}$ and growth becomes independent of the size of the labor force. It is worth emphasizing this result.

Result 3. In the oligopolistic economy, the scale effect is positive but vanishes asymptotically. In the monopolistically competitive economy, the scale effect is always zero.

This result implies that if the labor force, $L$, grows at a constant rate, the oligopolistic economy described in this paper converges to monopolistic competition. As this happens, the number of firms grows at the same rate as population while the rate of growth of the economy does not change. (In Fig. 2, the FF locus shifts out and traces the NN locus.) It is, therefore, possible to introduce population growth in this class of models without the counterfactual prediction of explosive growth rates. This property deserves attention and suggests an important direction for future research.

\section{Growth, market structure, and welfare}

In this section, I compare the market solution to the growth path that maximizes social welfare in order to evaluate the performance of the economy.

\subsection{The optimal choice of growth and variety}

Utility maximization requires symmetric consumption of all goods. Substituting the production technology (5) into Eqs. (1) and (2) yields the lifetime utility 
function to be maximized subject to

$$
\begin{aligned}
& \dot{N}=\left(L-L_{X}-L_{Z}\right) / \beta, \\
& \dot{Z}=\left(L_{Z} / N\right)^{\gamma} Z,
\end{aligned}
$$

$\dot{N} \geq 0$ and $\dot{Z} \geq 0$. The corresponding current value Hamiltonian is

$$
\mathrm{CVH}_{\mathrm{SP}}=\ln L_{X}+\theta \ln Z+\frac{1}{\varepsilon-1} \cdot \ln N+\frac{\mu}{\beta}\left[L-L_{X}-L_{Z}\right]+\xi\left(\frac{L_{Z}}{N}\right)^{\gamma} Z,
$$

where $\mu$ and $\xi$ are the shadow values of variety and knowledge, employment in manufacturing and $\mathrm{R} \& \mathrm{D}, L_{X}$ and $L_{Z}$, are the control variables, and average knowledge, $Z$, and the number of firms, $N$, are the state variables.

The first-order conditions are given by the dynamic constraints on average knowledge and the number of firms, by the transversality conditions on $N$ and $Z$, and by

$$
\begin{aligned}
& \frac{\theta}{\xi Z}+\left(\frac{L_{Z}}{N}\right)^{\gamma}=\rho-\frac{\dot{\xi}}{\xi}, \\
& \frac{1}{\varepsilon-1} \cdot \frac{1}{\mu N}-\frac{\xi Z}{\mu N} \gamma\left(\frac{L_{Z}}{N}\right)^{\gamma-1}=\rho-\frac{\dot{\mu}}{\mu}, \\
& \frac{\mu}{\beta}=\frac{\xi Z}{N} \gamma\left(\frac{L_{Z}}{N}\right)^{\gamma-1}, \\
& \frac{1}{L_{X}}=\frac{\mu}{\beta} .
\end{aligned}
$$

Note now that Eq. (34) implies $\xi Z=\theta / \rho$ at all times. Eqs. (36) and (37) yield

$$
\frac{L_{Z}}{N}=\left[\frac{\gamma \theta}{\rho} \cdot \frac{L_{X}}{N}\right]^{1 /(1-\gamma)} .
$$

This is the closed-form solution for the policy function for the optimal path. Using Eq. (38) and the definition $g \equiv \theta\left(L_{Z} / N\right)^{\gamma}$, the system can be written in $(N, g)$ space. When entry is feasible, employment in all activities must be positive and

$$
L>L_{X}+L_{Z}
$$

holds. This identifies the entry region $0 \leq g<\bar{g}(N)$, where $\bar{g}(N)$ is defined by

$$
\frac{L}{N}=\frac{\rho}{\gamma \theta}\left(\frac{g}{\theta}\right)^{(1-\gamma) / \gamma}+\left(\frac{g}{\theta}\right)^{1 / \gamma} .
$$


After some manipulations, the dynamics in the entry region are described by

$$
\begin{aligned}
& \frac{\beta(1-\gamma)}{\gamma} \cdot \frac{\dot{g}}{g}=\frac{\rho \varepsilon}{\gamma \theta(\varepsilon-1)}\left(\frac{g}{\theta}\right)^{(1-\gamma) / \gamma}-\rho \beta-\frac{L}{N}, \\
& \beta \cdot \frac{\dot{N}}{N}=\frac{L}{N}-\frac{\rho}{\gamma \theta}\left(\frac{g}{\theta}\right)^{(1-\gamma) / \gamma}-\left(\frac{g}{\theta}\right)^{1 / \gamma} .
\end{aligned}
$$

Differently from the market equilibrium, the optimal path is described by a two-dimensional system of differential equations. This is because the policy function (38) can be used to eliminate one variable from the system. I discuss dynamics in the technical Appendix available on request, here I focus on the steady state of the system.

\subsection{Market performance}

In steady state, the social optimum can be described as the intersection of the equivalent of the FF and NN loci discussed for the market equilibrium. Setting Eq. (41) equal to zero yields Eq. (39). This is the $\mathrm{FF}^{*}$ locus, the locus of the full-employment, optimal labor allocations. Next, setting (40) equal to zero and substituting (39) into the resulting expression yields

$$
\beta=\frac{1}{\gamma \theta(\varepsilon-1)}\left(\frac{g}{\theta}\right)^{(1-\gamma) / \gamma}-\frac{1}{\rho}\left(\frac{g}{\theta}\right)^{1 / \gamma} .
$$

This is the $\mathrm{NN}^{*}$ locus, the locus of the 'no-arbitrage', optimal labor allocations. This locus is best understood as the locus where the marginal utility of growth is equal to the marginal utility of variety, or, writing down the string of equalities $\theta / \xi Z=\rho=\beta \theta / \mu N$, as the locus where the social rate of return to knowledge is equal to the social rate of return to variety.

The first thing to notice is that Eq. (39) is identical to Eq. (28). Moreover, the only difference between Eq. (42) and Eq. (29) is the term $N /(N-1)$. This term is larger than one and, therefore, the $\mathrm{NN}^{*}$ locus lies everywhere below the $\mathrm{NN}^{*}$ locus in $(N, g)$ space. More precisely, the $\mathrm{NN}^{*}$ locus is exactly the asymptote toward which the NN locus converges when the number of firms becomes very large. Hence, in a model of monopolistic competition the $\mathrm{NN}$ and $\mathrm{NN}^{*}$ loci are identical and the market equilibrium is optimal. In the oligopoly model, in contrast, the market converges to a steady state where the economy grows too little and there are too many firms. At first sight, this result might seem paradoxical and is worth emphasizing.

Result 4. In the oligopolistic economy, the market provides too much variety and too little growth; as the number of firms becomes large, the market approaches asymptotically the social optimum. In the monopolistically competitive economy, the market achieves the social optimum. 
To explain these results, observe that in this economy there are no spillovers across firms in the R\&D technology (Eq. (6)). That is, dynamic increasing returns to $R \& D$ are internal to the firm. The only external effect in $R \& D$ is the spillover from incumbents to entrants whereby entrants can join the industry at the current average level of productivity upon sinking $\operatorname{cost} \beta$. Incumbents do not internalize this effect and plan R\&D according to their own output, ignoring the fact that part of the knowledge they develop benefits entrants. In steady state, there is no entry and this distortion is not operational. In addition, in this one-sector economy oligopolistic pricing does not give rise to distortions across industries, since all goods are priced in the same way. This explains why the FF locus coincides with the $\mathrm{FF}^{*}$ locus. The market satisfies the labor market clearing condition by allocating the optimal amount of labor to R\&D. In contrast, the market satisfies the no-arbitrage condition that the rate of return to entry equal the rate of return to $R \& D$ by allocating to $R \& D$ less labor than optimal. This is captured by the fact that the NN locus lies everywhere below the $\mathrm{NN}^{*}$ locus. This result depends on the assumption that, in Bertrand oligopoly, firms face a price elasticity of demand that is decreasing in the market share. As stated above, if one assumes atomistic firms and monopolistic competition, one approximates $\eta=\varepsilon$ and the market achieves Pareto optimality. This argument makes clear that there is no paradox in the result that the oligopolistic economy provides more variety than the monopolistically competitive one. The reason is that oligopolistic firms face a price elasticity of demand that is lower than the elasticity of product substitution. That is, they face 'softer' competition in the sense of Sutton (1991). As a consequence, they face a weaker business-stealing effect and a lower rate of return to R\&D. They thus spend less on R\&D. This means that the R\&D-cost effect is weaker and that the market accommodates more firms. This explains why an increase in the size of the economy, an increase in $L$, is Pareto improving. The increase in the number of firms leads to tougher competition and higher R\&D spending thereby offsetting the positive effect of the larger market size on the rate of return to entry.

The Pareto inefficiency discussed so far derives from oligopolistic pricing, where markups over marginal costs are endogenous and depend on the number of firms. It is interesting that even in a one-sector economy such markup pricing gives rise to distortions because of its effect on R\&D spending and the endogenous determination of market structure. This point is worth emphasizing.

Result 5. Oligopolistic pricing is the only distortion in the steady state of this economy; there are no operational externalities due to knowledge spillovers.

The distortion related to knowledge spillovers from incumbents to entrants arises only along the transition and it is one of the reasons why the market equilibrium is described by a three-dimensional system of differential equations while the optimal path can be reduced to two dimensions. 


\section{Conclusion}

In this paper, I explored the interaction of market structure and growth in a general equilibrium model of endogenous technological progress. I did not emphasize public knowledge and spillovers. In this model, firms accumulate knowledge without bound because of dynamic economies of scale internal to the firm. To take advantage of increasing returns, $R \& D$ resources must be concentrated. This identifies a trade-off between growth and the number of firms. Another trade-off arises from the endogeneity of market structure. In free-entry equilibrium, R\&D expenditures are one component of firms' total costs and are negatively related to the number of firms. A third trade-off arises because production and R\&D compete for resources. Since aggregate employment in production increases with the number of firms, expanding the number of goods requires reducing $R \& D$ and growth.

These trade-offs capture the dynamic interdependence of price, $\mathrm{R} \& \mathrm{D}$, and entry decisions and produce interesting results. For example, the scale effect is bounded from above and converges to zero as the number of firms in the market grows very large. When population increases, the larger market leads to entry and a larger number of firms. This induces dispersion of $R \& D$ resources across firms that offsets the positive effect of the larger market on the returns to R\&D. This intuition is quite general and suggests that properly taking into account the role of market structure is likely to improve our understanding of long-run growth. These ideas extend to the normative analysis. When the number of firms is endogenous, market performance involves two dimensions: the rate of growth of consumption of each good and the variety of consumption goods. The trade-off between these two dimensions leads to a Pareto inefficient allocation of resources. The market grows too little and supplies too much variety. This result is not due to technological externalities but to oligopolistic pricing and the interaction between R\&D and entry. This preliminary exploration sets the agenda for future research. It is imperative, for example, to check the robustness of these results to the inclusion of technological spillovers. These generate distortions, not considered in this paper, that might interact in unexpected ways with the one emphasized here.

\section{Acknowledgements}

This paper develops chapter 4 of my Ph.D. dissertation. I thank Richard Levin and Xavier Sala-i-Martin for their time, encouragement and advice. I thank my former classmates at Yale for useful discussions in the Macroeconomics Prospectus Workshops and in the Growth Lunch Seminar. Finally, I thank Willem Buiter, Nouriel Rubini, Chris Sims, T.N. Srinivasan, Sjak Smulders, seminar participants at Columbia, Johns Hopkins, Duke, and SUNY 
at Stony Brook, and two anonymous referees for valuable and detailed comments. All errors are my responsibility. The first version of this paper circulated under the title "Dynamic Market Structure and Economic Growth" in the Fall 1993.

\section{References}

Aghion, P., Howitt, P., 1992. A model of growth through creative destruction. Econometrica 60, $323-351$.

Baldwin, W., Scott, J., 1987. Market Structure and Technological Change. Harwood Academy, New York.

Cohen, W., Levin, R., 1989. Empirical studies of market structure and innovation. In: Schmalensee, R., Willig, R. (Eds.), Handbook of Industrial Organization. North Holland, Amsterdam.

Dasgupta, P., Stiglitz, J., 1980. Industrial structure and the nature of innovative activity. Economic Journal 90, 266-293.

Dosi, G., 1988. Sources, procedures, and microeconomic effects of innovation. Journal of Economic Literature 36, 1120-1171.

Fershtman, C., Mueller, E., 1984. Capital accumulation games of infinite duration. Journal of Economic Theory 33, 322-339.

Fudenberg, D., Tirole, J., 1991. Game Theory. MIT University Press, Cambridge.

Grossman, G., Helpman, E., 1991. Innovation and Growth in the Global Economy. MIT University Press, Cambridge.

Kamien, M., Schwartz, A., 1982. Market Structure and Innovation. Cambridge University Press, Cambridge.

Lee, T., Wilde, L., 1980. Market Structure and Innovation: A reformulation. Quarterly Journal of Economics 94, 431-436.

Loury, G., 1979. Market structure and innovation. Quarterly Journal of Economics 93, 395-410.

Malerba, F., 1992. Learning by firms and incremental technical change. Economic Journal 102, 845-859.

Nelson, R., Winter, S., 1982. An Evolutionary Theory of Economic Change. The Belknap Press of Harvard University Press, Cambridge.

Romer, P., 1990. Endogenous technological change. Journal of Political Economy 98, S71-S102.

Scherer, F., Ross, D., 1990. Industrial Market Structure and Economic Performance. Houghton Mifflin, Boston.

Schumpeter, J., 1928. The instability of capitalism. Economic Journal 38, 361-386.

Schumpeter, J., 1942. Capitalism, Socialism, and Democracy. Harper and Row, New York.

Spence, M., 1984. Cost Reduction, Competition, and Industry Performance. Econometrica 52, $101-121$.

Sutton, J., 1991. Sunk Costs and Market Structure. MIT University Press, Cambridge.

Thompson, P., Waldo, D., 1994. Growth and trustified capitalism. Journal of Monetary Economics 34, 445-462.

Tirole, J., 1988. The Theory of Industrial Organization. MIT University Press, Cambridge. 